\title{
The Market-agents' Model of the Prices Variation Mechanism
}

Wen ZHENG $^{1, a}$, Shi ZHENG ${ }^{2}$, Kong-Wang WANG ${ }^{1}$

${ }^{1}$ School of Economics and Trading, Northeastern University at Qinhuangdao, P. R. China

${ }^{2}$ School of Management, Dalian Minority University, P. R. China

aresearcherzw@126.com

Key words: Market-agents, Price mechanism, CAS modeling, PVM.

\begin{abstract}
Market prices were affected by the market-agents. The market-agents behaved as many factors, such as the behaviors of the market players, the hot money etc., which cause the variation of the market prices. Based on the behaviors of the intermediate merchants of the market, the paper applies the complex adaptive system theory and feedback method to explore the variation of the market prices mechanism. It abstracts out a mathematical system equation to describe the theoretical model. Then analyze the strategy jump between the market reseller principles. The paper points out the main factors of the market price movement, and reveals that the prices will respond to the market excess demand constantly adjusted by the market-agents.
\end{abstract}

\section{Introduction}

The price mechanism is the formation and operation mechanism of market price which influence and control with supply and demand in the competitive process. It includes price formation mechanism and price adjustment mechanism. The price mechanism which is the most sensitive and effective regulatory mechanism in the market has an important impact on the whole social economic activities. It reflects the connection and interaction between variation of the price and the change of supply and demand In the process of market competition. The variation of commodity prices will cause supply-demand relationship changes, which in turn cause the change in price.

There has been a mature research system of price Variation mechanism. Frank Westerho(2003) analyzed the classification of market-agent (the main market players) types and the revenue function of each type. Based on the condition of investors' limited rationality, the variation of price will change the benefits of each player, so as to remove the vicious competitor and maintain the stable state of market. Peter Heemeijer(2009) studied the influence forward and reverse feedback have on price stability and volatility. This article used the feedback control theory to prove the change of the input conditions will affect the frequency of price volatility by experimental method. This article also simulated the market state after the input conditions changed by using the simulation software. Guillermo Fernandez-Anaya et al (2007) added the feedback function under the premise of Walras hypothesis in economics to change price to the wanted prices variation mechanism dynamically. Newton and Jacobi method and derivative feedback control strategy were used to make the excess demand function (called $Z(p)$ ) to converge to a equilibrium point where $Z(p)=0$ by the solution channel path $p(t, p o)$ guaranteed by prices variation mechanism, thus the reasonable threshold scope of prices change is obtained. In modeling of price regulation mechanism, D.Saari and Simon (1978) found that the appropriate excess demand dependence is not enough, the whole Jacobian matrix must be used to converge to a equilibrium price which meet almost all the initial conditions. In fact, Jacobian matrix contains important information to guide price changes under the condition of excess demand. There have been some domestic research focuses on the excessive high commodity prices in recent years. To sum up, price is not only a product of supply-demand relation ship but also the result of game among market participants under the background of China's network 
market. Price which is the product generated by complex adaptive system (CAS) is the input condition of system in the recycling game process as other market conditions. Cycle time period decided to variation period, frequency and threshold of price. Some researchers have studied the mechanism of price formation and variation, while researches on more detailed and practical price mechanism, especially on the mechanism of abnormal price variation are not serious enough. This paper studies the price variation mechanism under the hypothesis of limited rationality, drive out malignant idle fund speculators by price restriction in order to explore the formation mechanism of price variation.

\section{The factors of the market-agents}

Market prices were affected by many factors under the background of socialist market economy. Price volatility is a result of the combined action of various factors rather than a single factor. A particular factor will play the prominent role only when price volatility sharply such as sudden natural disasters, a large number of speculators enter the market and hoard goods. Throughout all kinds of literatures, the impact factors can be divided into some types as following:

1) Uncontrollable factors.

2) Controllable factors of the market. The effective supply of goods is the kinds of the market controllable factors.

3) Controllable factors of the capital. The types of idle fund are the other kinds of the market controllable factors. At present, government has yet to implement macroeconomic regulation for commodity such as supporting the acquisition. The loopholes still exist in the commodity macroeconomic regulation. In order to obtain excess profits, speculators will raise money to hoard goods to control the market price. This is the main factor which is the focus of this paper.

4) Other factors. Unsound market mechanism, high level of inflation, rising expectations based on the low price level before and so on.

In brief, commodity price volatility which is the outcome of multiple factors' combined action is a complex system problem.

\section{The theoretical model of the market-agents}

The author applies complex adaptive system theory and the feedback method to study the prices variation mechanism based on literature analysis and related research. The qualitative analysis method is used to discuss the problem of prices variation mechanism. The phenomenon of commodity market price volatility results from the interaction of market-agents in the market environment. The Nobel prize-winning economist Arrow proposed that low dimensional variables and parameters can be used to describe economic system which is in dynamic evolution. In this way, the evolution of economic system and its various complex economic phenomena can be analyzed. The complexity of market can not be described by theoretical models sufficiently. In order to have clear concepts, the main bodies and trading behavior of commodity market are simplified in our model. We assume that the normal intermediate merchants can only trade a fixed number products and the speculators buy a large amount of products in low price level while throw up in high price. The transition probability is applied to describe the change of trading strategies and behavior of market prices variation.

For sellers, how to make a reasonable dynamic price under the supervision of Price Bureau at any sales time is a critical problem. The basic assumptions of mathematical model are as follows:

1) At the beginning $\left(t_{0}\right)$, the basic value price is $p_{c}$, which keeps a constant within a certain time. The market price is $p$ which changes with $t$.

2) $t>t_{0}$, volume of sales is $\delta$.

3) Price fluctuation of similar products and the obvious contradiction between supply and 
demand will make the sales price change. In $\Delta t$, the amount of price fluctuations is $\Delta p_{b}$. The amount of price fluctuations of similar products is $\Delta p_{1}$ and the amount of supply-demand fluctuations is $\Delta \delta$. The sale price volatility results from all the above factors are $\omega_{1}=\omega\left(\Delta p_{b}, \Delta p_{1}, \Delta \delta, \Delta t\right)$.

4) Basic parameters and variables of market-agents trading model are as follows:

Num: the number of the market intermediate merchants

$N_{\text {foud }}$ : the number of the normal intermediate merchants

$N_{\text {spec }}$ : the number of speculators

$N_{\text {opti }}$ :the number of optimistic speculators

$N_{\text {pess }}$ :the number of pessimistic speculators

5)the following three variables are used to describe the state of the market:

$C I=\left(N_{\text {opit }}-N_{\text {pess }}\right) / N_{\text {spec }}$, CI expresses the power comparison between optimistic speculators and pessimistic speculators. It can reflect whether the market atmosphere is good or not.

$S I=\left(N_{\text {opit }}-N_{\text {pess }}\right) /$ Num, which is called speculative index in this paper expresses the power comparison between the distinction between optimistic speculators and pessimistic speculators and the number of the market intermediate merchants.

$R I=N_{\text {foud }} /$ Num, the proportion of normal intermediate merchants, is called rationality index in this paper.

We use CI P, SI, RI and price index P to describe the market condition and make judge-ment of current market status according to the rationality of these indexes.

We assume that Num market intermediate merchants sell the same product and divide intermediate merchants into two types: normal intermediate merchants and speculators. At time t, the number of normal intermediate merchants is $N_{\text {foud }}$, respectively the number of speculators is $N_{\text {spec }}$. Obviously, Num $=N_{\text {spec }}+N_{\text {foud }}$. The speculators can be divided into two types: optimistic ( $\left.N_{\text {opti }}\right)$ and pessimistic speculators $\left(N_{\text {pess }}\right)$. Obviously, $N_{\text {spec }}=N_{\text {opti }}+N_{\text {pess }}$.

The market intermediate merchants will change one type into another due to the nature of chasing profits.

Due to herd mentality, there will be a tendency that market-agents tend to chase prices. Thus, the products market may be like the stock market, which change from bad market into good one, or from the good market to the bad one. Under the influence of market environment, the market intermediate merchants adjust their business model. The new market status will be formatted in this evolution and development.

\section{The transfer between the speculative merchants}

When meet merchant with different types, the market intermediate merchant will compare the profits and a proportion of type conversion will appear. For example, some normal intermediate merchants may become optimistic speculators.

We assume $\lambda$ is basic profit, $R$ is the average return rate of capital investment. Optimistic speculators will buyout the products and the super-profit they acquired is $(\lambda+d p / d t) / p$. While pessimistic speculators sell some products, the super-profit of pessimistic speculators is $R-\lambda-d p / d t$.

When $R=\lambda / p_{c}$, and $p=p_{c}$, then $d p / d t=0$, the return rate of investment on products is equal to other social investment. The normal intermediate merchants think the market price is rational and the rational average return rate $R=\lambda / p_{c}$ will be taken. The profit is the differentials between the 
price and the basic value, $\left|\left(p-p_{c}\right) / p\right|$. Therefore, the probability of strategy transformation in different types of intermediate merchants can be expressed by formula 1-6.

$$
\begin{aligned}
& \phi_{f \rightarrow o p}=v^{*} \exp \left(\theta_{21}\right) \\
& \phi_{o p \rightarrow f}=v^{*} \exp \left(-\theta_{21}\right) \\
& \phi_{f \rightarrow p e}=v^{*} \exp \left(\theta_{22}\right) \\
& \phi_{p e \rightarrow f}=v^{*} \exp \left(-\theta_{22}\right) \\
& \theta_{21}=\alpha\left(\frac{\lambda+\frac{d p}{d t^{*} v}}{p}-R-\left|\frac{p-p_{c}}{p}\right|\right) \\
& \theta_{22}=\alpha\left(R-\frac{\lambda+\frac{d p}{d t^{*} v}}{p}-\left|\frac{p-p_{c}}{p}\right|\right)
\end{aligned}
$$

$\phi_{f \rightarrow o p}$, the probability that normal intermediate merchants change into optimistic speculators;

$\phi_{f \rightarrow p e}$, the probability that normal intermediate merchants change into pessimistic speculators;

$\phi_{p e \rightarrow f}$, the probability that pessimistic speculators change into normal intermediate merchants;

$\phi_{o p \rightarrow f}$, the probability that optimistic speculators change into normal intermediate merchants;

$v$, the change frequency of different types;

$\alpha$, the coefficient of intermediate merchants transformation probability.

\section{The transfer between the optimistic speculative merchants and the pessimistic ones}

When choosing business strategies, speculators will consider the trend of price variation, the interaction of different market-agents and the effect of other factors.

As we analyzed above, CI can reflect whether the market atmosphere is good or not. Its expression is $C I=\left(N_{\text {opti }}-N_{\text {pess }}\right) / N_{\text {spec }}$. The effect on strategy transformation can be express by formula 7.

$$
\theta_{1}=\beta * C I+\gamma \frac{\dot{p}}{v^{\prime}}
$$

The probability that pessimistic speculators change into optimistic speculators can be expressed by formula 8 . While the probability that optimistic speculators change into pessimistic speculators can be expressed by formula 9 . 


$$
\begin{aligned}
& \phi_{o p \rightarrow p e}=v^{*} \exp \left(\theta_{1}\right) \\
& \phi_{p e \rightarrow o p}=v^{*} \exp \left(-\theta_{1}\right)
\end{aligned}
$$

Where, $\dot{p}=d p / d t$ is derivative for time. $v^{\prime}$ is the frequency that intermediate merchants reappraise and change their strategies. $\beta$ and $\gamma$ are the weights of two factors (herd mentality and price tracking) when the intermediate merchants make decisions.

\section{Conclusion}

Supposing the speculate merchants trade in a fix amount $t_{\text {spec }}$, their overdue demand is $E D_{\text {spec }}$ which is the product of difference between optimists and pessimists $\left(N_{\text {opti }}-N_{\text {pess }}\right)$ and the average trading volume $t_{\text {spec }}$, that is $E D_{\text {spec }}=\left(N_{\text {opti }}-N_{\text {pess }}\right) * t_{\text {spec }}$. The normal intermediate merchants will insist on trading according to the basic value, their overdue demand function is $E D_{\text {foud }}=N_{\text {foud }} *\left(p_{c}-p\right)$. Thus, we can get the total overdue demand is $E D=E D_{\text {spec }}+E D_{\text {foud }}$.

Market prices will respond to overdue demand in the market and change with time according to the total overdue demand $E D$. The adjusted market price is $\Delta p=\varepsilon E D, \varepsilon$ is the degree of reaction to the overdue demand.

In this paper, product market model is established based on CAS theory and the theoretical model of prices variation mechanism are analyzed. We also abstract out a mathematical system equation to describe prices variation mechanism model.

\section{References}

[1] D. Saari, V.T. Simon, Effective price mechanisms, Econometrica 46 (1978) 1097-1125.

[2] Frank Westerho. Speculative markets and the effectiveness of price limits. Journal of Economic Dynamics \& Control[J] 28 (2003) 493 - 508.

[3] Guillermo Fernandez-Anaya, Jose Alvarez-Ramirez, Carlos Ibarra-Valdez. On feedback and stable price adjustment mechanisms [J]. Physica A, 2007, (377):211-226.

[4] Peter Heemeijer, Cars Hommers, Joep Sonnemans, Jan Tuinstra. Price stability and volatility in market with positive and negative expectations feedback: an experimental investigation[J]. Journal of Economic Dynamics \& Control, 2009, (33):1052-1072. 